\title{
Profiles of Emerging Adult Online Daters and Psychosocial Cognitions about Condom Use
}

\author{
Shaha Aziz, Tiffany Ewere, Karina Serrano, Chakema Carmack* \\ Psychological, Health, \& Learning Sciences Department, University of Houston, Houston, TX, USA \\ Email: *ccarmack@central.uh.edu
}

How to cite this paper: Aziz, S., Ewere, T., Serrano, K., \& Carmack, C. (2021). Profiles of Emerging Adult Online Daters and Psychosocial Cognitions about Condom Use. Open Journal of Social Sciences, 9, 198-213. https://doi.org/10.4236/jss.2021.97014

Received: May 26, 2021

Accepted: July 17, 2021

Published: July 20, 2021

Copyright $\odot 2021$ by author(s) and Scientific Research Publishing Inc. This work is licensed under the Creative Commons Attribution International License (CC BY 4.0).

http://creativecommons.org/licenses/by/4.0/

\begin{abstract}
Online dating provides emerging adults with a way of connecting with others more frequently and efficiently than traditional courtship. Online dating sites pose opportunities for relationships and sexual encounters, which may be accompanied by engagement in sexual risk behaviors, such as lack of condom use. The present study used the theory of planned behavior to explore psychosocial cognitions (i.e. constructs) about condom use among online daters. The sample size consisted of $\mathrm{N}=156$ emerging adults $\left(\mathrm{M}_{\text {age }}=20.6\right)$ who participated in an online survey of health behaviors and sexual risk. Using attitudes, subjective norms, and self-efficacy about condom use, latent class analysis identified four latent classes: Consistent Condom Users (17\%), Inconsistent Condom Users with Low Dating Site Usage (23\%), Inconsistent Condom Users with High Dating Site Usage (40\%), and Consistent Condom Non-Users (20\%). Consistent Condom Non-Users had the highest probability of utilizing dating sites $2+$ hours per day, the highest probability of low self-efficacy and low subjective norms about condom use, and a zero probability of using a condom. Inconsistent Condom Users with Low Dating Site Usage and Inconsistent Condom Users with High Dating Site Usage varied in their attitudes and self-efficacy toward condom use. Consistent Condom Users were low on dating site usage, high on all psychosocial constructs, and had a $100 \%$ probability of using a condom. Results highlight the need to further explore interventions throughout college campuses and online within dating sites, to strengthen attitudes, subjective norms, and self-efficacy toward condom use among online dating emerging adults.
\end{abstract}

\section{Keywords}

Online Dating, Condom Use, Latent Class Analysis, Psychosocial Constructs

\section{Introduction}

New media is known as any media delivered digitally through internet-based 
mediums (The New Media Institute, University of Georgia-Athens, n.d.). Social media is a popular form of new media. It is estimated that Americans spend around 2 hours and 6 minutes per day utilizing social media platforms; and people aged 16 to 24, which include both late-adolescence and emerging adulthood, spend about 3 hours and 1 minute per day using social media (Salim, 2019). It is clear that social media networking is currently a part of some adults' daily lives. Social media platforms (e.g., Facebook and Instagram) make it much easier for people to connect with one another. These platforms provide emerging adults with a way of connecting with others more frequently and efficiently than before. The connections made could be friendly and provide positive social interactions online, but could also lead to in-person interactions through group meet-ups and directly requesting to meet in-person, for example. Previous research has shown that social media usage, in general, has been associated with sexual risk behaviors among young adults (Carmack \& Rodriguez, 2018). Online dating, a sub-category of social media networking, involves the pursuit of relationships, whether meaningful or casual. In many cases, such pursuits, at some point, may involve engagement in consensual sexual relationships.

\subsection{Online Dating and Sexual Risk Behavior}

Online dating sites such as Tinder, Bumble, Match.com, eHarmony, and many others pose opportunities for sexual encounters, as these social media platforms host online dating and are specifically marketed for those wishing to engage in relationship seeking. Almost 25\% of Americans reported that they have been on at least one date with a person they met online (Pew Research Center, 2020). Online dating is particularly popular among emerging adults, ages 18 - 29. Within this age range, it is estimated that $47 \%$ have engaged in online dating activity at some point in their lives, with about $20 \%$ reporting that they found their spouse or another long-term/meaningful relationship via online dating (Pew Research Center, 2020). While many online dating encounters may begin with the search for true love or a meaningful relationship, they could also begin with the intention of having a "hook-up" (i.e. casual sex), which could increase the risk of unsafe sexual practices during an in-person encounter (Carmack \& Rodriguez, 2018).

Online dating may offer users a potentially more playful space than traditional courtship, but can also be problematic regarding sexual expectations and behavior (Whitty \& Carr, 2006). According to Couch and Liamputtong (2008), the primary reasons for online dating were to find a soul mate, have sex, have fun, to relax, to ease boredom, and that it is an easy way to meet people. Themes related to the decision to meet in-person included having access to the person's photos, rapport, being mentally attracted to the person, and the ability to have sex quickly. Among the qualitative sample of $\mathrm{N}=15$, sexual encounters varied greatly, with some participants engaging in sex with every person with whom they met in-person. Most reported engaging in sex with about 1 in every 4 of the 
people they met in-person from dating sites. Overall, the study indicated that online dating allowed people to expand their sexual networks and engage in "more sex." Likewise, Choi et al. (2016a) found that that, among N = 260 college students, those who used online dating apps for more than 12 months (relative to nonusers) were 3.21 times more likely to have engaged in casual sex, even when controlling for other factors such as age, income, gender, and sexual orientation.

Unprotected sex is a sexual risk behavior that increases the likelihood of contracting sexually transmitted diseases (STIs). Regarding unprotected sex and online dating, previous research has shown that the use of dating apps was significantly related to unprotected sex (Choi et al., 2016b). Dating app users were 1.9 times more likely to have not used condoms during their last sexual intercourse and were $48 \%$ less likely to report consistent condom use. Bisexual/homosexual participants were 2.6 times more likely to have not used condoms during their last sexual intercourse (compared to heterosexual participants); and female participants were 2 times more likely to have not used condoms during their last sexual intercourse than males. Among heterosexual men who use online dating apps, those with a higher number of sexual partners were less likely to discuss their STI history with their partner, nor did they intend to use a condom with a new sexual partner (Cheng et al., 2018). Given that online dating is associated with condomless sex, a greater number of sexual partners, and inconsistent condom use, research is needed to explore factors associated with sexual risk behaviors among online daters, specifically.

\subsection{Theoretical Framework}

The theory of planned behavior (TPB; Ajzen, 1991) has been used throughout the literature to address sexual risk behavior among many subpopulations. Briefly, the TPB posits that attitudes, subjective norms, and self-efficacy are psychosocial constructs of behavior that have the ability to predict intentional and actual behavior (e.g. condom use). Attitude is the positive or negative effect of a behavior (e.g. whether you like using condoms or not); subjective norms are individual evaluations of whether one believes significant others would approve them performing the behavior (e.g. one believes that important others think they should use a condom); and self-efficacy is the situation-specific ability to carry out a behavior (e.g. the practical ability to use a condom).

The TPB has been utilized previously throughout public health and psychology research in predicting condom use intention and behavior (Carmack \& Lewis, 2009; Gibson et al., 2020; Gomes \& Nunes, 2017; Montanaro et al., 2018; Morales et al., 2021; Robison-Chadwell, 2017; Turchik \& Gidycz, 2012). Gomes and Nunes (2017), found the TPB to be a useful model in predicting condom use intentions among adolescents; and specifically, that attitudes and subjective norms were significantly predictive of condom use. Much of the previous research on the TPB and sexual risk behavior has been conducted on adolescent populations 
and other special populations (e.g. commercial sex workers). However, young adults are still in need of intervention messaging regarding condom use as an STI prevention strategy.

Using the self-efficacy construct, Carmack et al. (2020) found that high self-efficacy for condom use communication was significantly predictive of condom use among a sample of young adult college students $(\beta=.32, p=.02)$. Furthermore, there may be a priming effect of attitudes within traditional media (e.g. movies and television shows). Individuals may be primed to believe that persons who engage in sexual activity face minimal or no consequences to their actions, thereby altering or influencing their attitudes toward safer sex practices (Eggermont, 2004; Hansen \& Krygowsky, 1994; Martino et al., 2006; Ward, 2003; Ward \& Friedman, 2006). It is logically possible that this priming effect could be mimicked within the social media online environment as well. Poor attitudes, subjective norms, and self-efficacy toward condom use could be detrimental to individual health and public health when understanding that frequent, casual, unprotected sex and multiple partners increase one's risk of contracting an STI and other unwanted situations.

\subsection{Study Purpose}

Although the aforementioned studies demonstrated associations between the TPB constructs and sexual risk behavior, they did not examine online dating practices as primary factor. The TPB has not been widely used to examine consistent condom use among young adult online daters.

The present study used the TPB constructs to examine condom use among online daters. Despite extant research on TPB and sexual risk behavior, little is known about the interplay of TPB constructs among emerging adults who are online daters. Therefore, the purpose of the present study was to identify latent (unobserved) classes of online daters that take into account multiple coexisting TPB psychosocial constructs. This approach serves to provide information about class membership indicated by the TPB psychosocial constructs and consistent condom use. Latent classes were estimated that allowed us to identify and enumerate online dating classes pertaining to unique combinations of psychosocial constructs (probabilities), as well as estimate the prevalence of the classes within this sample of emerging adult online daters.

\section{Methods}

\subsection{Participants}

Participants included $\mathrm{N}=331$ emerging adults attending a large minority-serving institution (MSI). Participants reported a mean age of $\mathrm{M}=19.7, \mathrm{~s}=$ 1.6. Forty-seven percent $(\mathrm{N}=156)$ of the sample indicated that they had an online dating account that they had logged into within the past 3 months and reported being sexually active within the past three months. Thus, the analytic sample for the present study consisted of $\mathrm{N}=156$ college students. 


\subsection{Procedure}

The present cross-sectional study was approved by the institution's internal review board, and recruitment was initiated via the university's research participation platform. Participants wishing to participate were informed and consented electronically to participate in a sexual health and wellness survey. Participants were informed that their responses would remain anonymous and used as aggregate data only. Eligibility included being officially enrolled as a university student. Participants were administered a 26 -item secure online survey that included sexual health behaviors (e.g. condom use, STI history), online dating behaviors, and psychosocial constructs related to sexual health and wellness. Survey participation took approximately 7 minutes.

\subsection{Measures}

Demographics and Online Dating Reporting. Demographics included five items which were biological sex, age, classification, race, ethnicity, and sexually active within the past three months. Online dating was captured by a two-part item that first, asked participants whether they had an active account on a dating website, such as eHarmony, Plenty of Fish, Tinder, etc.; and secondly, asked participants to estimate, on average, about how many minutes/hours they spent interacting on all dating sites, combined, per day.

Attitudes. Attitudes toward condom use included six items adopted from previous research on psychosocial constructs regarding condom use (Carmack et al., 2015) that asked participants to rate their level of agreement to various condom use statements such as, "Sex still feels good when a condom is used." Attitude items were set to a 5-point Likert scale from strongly disagree (1) to strongly agree (5). These items had a reliability of .94 .

Subjective Norms. Subjective norms included six items adapted from previous research on psychosocial constructs regarding condom use (Carmack et al., 2015). Items indicating subjective norms asked participants a series of questions about the approval and disapproval of important others, such as, "My sexual partner would approve of using a condom." These approval items were cross multiplied by the level of motivation to comply (e.g., "I want to do what my sexual partner thinks I should do") (Trafimow \& Fishbein, 1994). Subjective norms items were set to a 5-point Likert scale from strongly disagree (1) to strongly agree (5). These items had a reliability of .93.

Self-efficacy. Self-efficacy included five items adopted from previous research on psychosocial constructs regarding condom use (Carmack et al., 2020). Items indicating self-efficacy asked participants about their perceived ability to use a condom in various partner situations such as, "Before we are ready to have sex, I can talk to my partner about using a condom." Self-efficacy items were set to a 5 -point Likert scale from strongly disagree (1) to strongly agree (5). These items had a Cronbach's reliability of .90 .

Condom Use. Condom use was captured with a single item that asked partic- 
ipants, "In the past 3 months, about how often have you used condoms during sexual intercourse: 1) Not at all 2) Sometimes 3) Half the time 4) Almost Always 5) Every time." Table 1 shows a complete list of all measured items, including the specific attitude, subjective norms, and self-efficacy items used in the present study.

\subsection{Analytic Procedure}

Latent class analysis (LCA) was used to identify unique groups of online daters and their coinciding psychosocial constructs and condom use. LCA is a Bayesian statistic that assigns probability values to the variables of interest and calculate unique combinations of their most likely classification group. LCA allowed us to interpret whether the variables of interest served to distinguish probable classifications. Analysis for the current study used Mplus Version 7.4. The following variables of interest, or latent indicators, were used in the present study to build the classification model.

Table 1. Online dating \& condom use items.

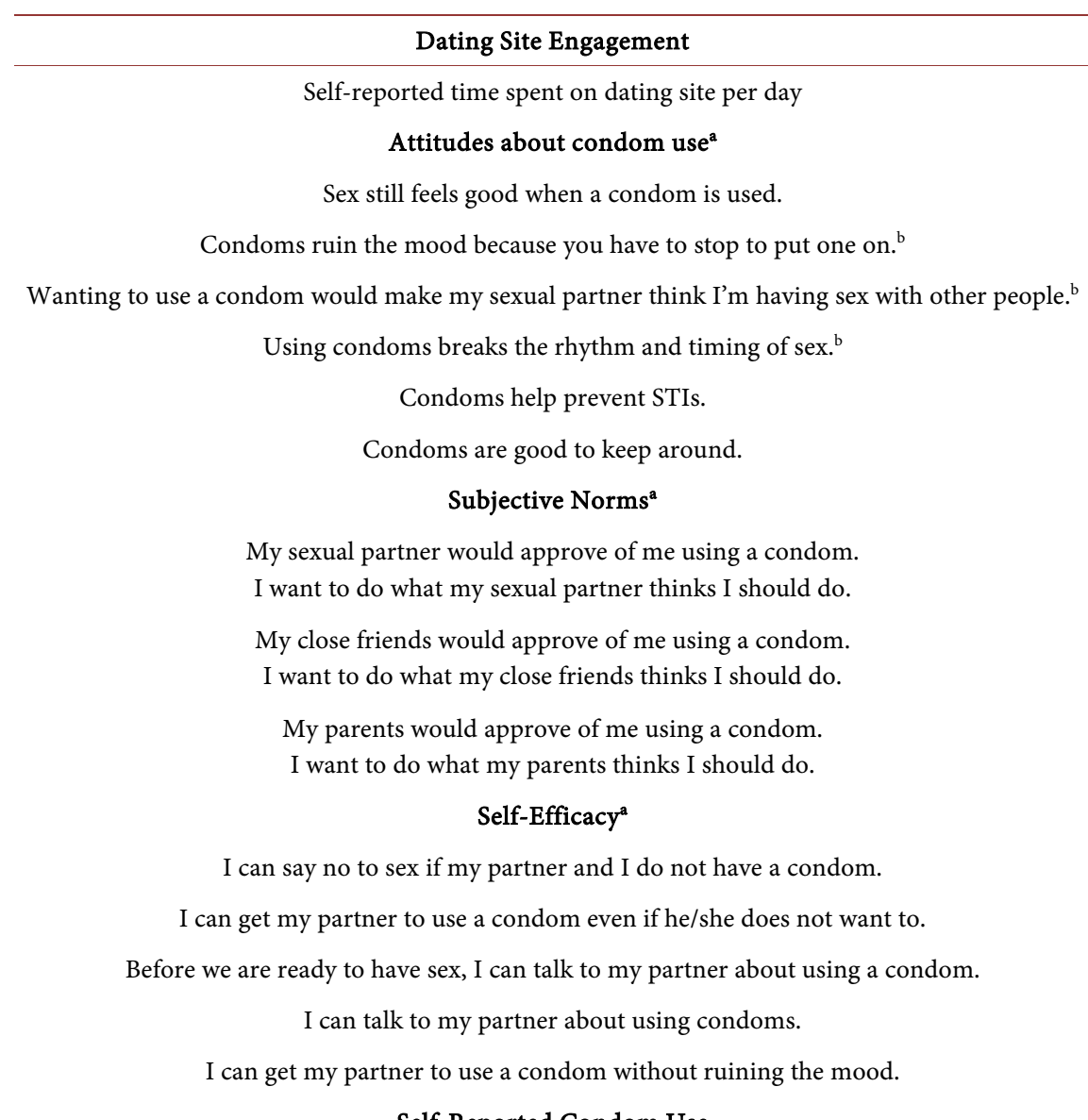

\section{Self-Reported Condom Use}

In the past 3 months, about how often have you used condoms during sexual intercourse?

a. Item scale: $1=$ Strongly Disagree $2=$ Disagree $3=$ Neither agree nor disagree $4=$ Agree $5=$ Strongly Agree; b. Item scale reverse coded: $1=$ Strongly Agree $2=$ Agree $3=$ Neither agree nor disagree $4=$ Disagree $5=$ Strongly Disagree. 
Online Dating Activity. Online dating activity for the present sample ranged from 20 minutes per day to 4.5 hours per day. The median value, $\tilde{x}=2.04$ was used as the cut point for high and low online dating usage (Boonstra et al., 2014). Thus, those who reported 2 hours or less per week of dating site usage were classified as low dating site users, and those who reported greater than 2 hours per week of dating site usage were categorized as high dating site users (0 = low; 1 = high).

Psychosocial Constructs. Items indicating attitudes, subjective norms, and self-efficacy were each summed to create a total composite value, and the median was used as the cut point for high and low categories. Attitudes resulted in a median score of $\tilde{X}=2.9$; Subjective norms resulted in a median score of $\tilde{X}=$ 4.1; and self-efficacy resulted in a median score of $\tilde{X}=3.4$. Participant values that were equal to or less than the median value were categorized as having pro-condom attitudes, subjective norms, or self-efficacy; and participant values that were greater than the median value were categorized as having less pro-condom attitudes, subjective norms, or self-efficacy $(0=$ no; $1=$ yes/pro-condom $)$.

Consistent Condom Use. Consistent condom use was calculated with the item that asks, “... about how often do you use condoms ...” 1) never, 2) rarely, 3) sometimes, 4) most of the time, and 5) all the time. Participants who answered (5) all the time, were categorized as consistent condom users. Those that reported (1)-(4) were categorized as inconsistent condom users $(0=$ no; $1=$ yes/consistent condom user).

A series of LCA models specifying one to five latent classes were tested using global maximum likelihood estimates. The optimal class solution (number of classes contained in the model) was chosen using the following standard LCA indices: the Bayesian Information Criteria (BIC and adjusted-BIC) and Akaike Information Criteria (AIC).

LCA analyses began with specifying one latent class. After examining the improvement in fit with one additional class specified, the best-fitting model was identified. If the class was not significantly different from the previous class (with one-less class), then the previous class is examined as the optimal class solution. Fit indices began to decline when specifying four classes. An additional configuration specifying a five-class solution was analyzed. Upon the model fit further declining, we chose the three-class model solution as the optimal solution. The best-fitting model was selected with consideration to the lowest log likelihood, AIC, BIC, and a-BIC values. Likelihood ratios (Lo-Mendell-Rubin/Likelihood Ratio Test) further demonstrated the optimal class solution model (Lo, Mendell, and Rubin, 2001). Lastly, entropy and interpretability of the classes during model selection was considered to ensure the final model selection makes conceptual sense (Nylund, Asparouhov, Muthén, 2007).

\section{Results}

The analytic sample consisted of $\mathrm{N}=156$ young adults attending a minority-serving higher education institution (MSI) in the Southern United States. Of 
this, the mean age was $M_{\text {age }}=20.6$; and consisted of $39 \%(N=61)$ Hispanic, $31 \%$ $(\mathrm{N}=49)$ African American, $16 \%(\mathrm{~N}=25)$ White, $10 \%(\mathrm{~N}=15)$ Indian and $4 \%$ $(\mathrm{N}=6)$ Asian identifying adults. Their self-reported classification was $13 \%(\mathrm{~N}=$ 21) Freshmen, 20\% ( $\mathrm{N}=32)$ Sophomores, $44 \%(\mathrm{~N}=67)$ Juniors, and $23 \%(\mathrm{~N}=$ 36) Seniors. All participants included in the present study analyses indicated having one or more active online dating profile on an online dating site with which they had interacted within the past month. Preliminary t-tests revealed no significant differences between the genders (male and female) and the model indicator variables. Likewise, preliminary ANOVA tests revealed no significant differences between the classifications and the model indicators variables.

LCA identified four latent classes based on the indicators: Class 1: Consistent Condom Users (17\%; $\mathrm{N}=27)$, Class 2: Inconsistent Condom Users with Low Dating Site Usage (23\%; N = 36), Class 3: Inconsistent Condom Users with High Dating Site Usage (40\%; N = 62), and Class 4: Consistent Condom Non-Users (20\%; $\mathrm{N}=31)$. Consistent Condom Users were characterized by a $100 \%$ probability of consistently using a condom during sexual intercourse (1.0). They showed a zero probability of spending two or more hours per day on dating site apps. This class also exhibited high probabilities of having pro-condom attitudes (.73), pro-condom subjective norms (.80), and high self-efficacy for condom use (.94). Inconsistent Condom Users with Low Dating Site Usage were characterized by having a zero probability of spending two or more hours on dating sites, as well as having a moderate probability of consistent condom use (.66). This class exhibited a high probability of having high self-efficacy for condom use (.78), but also a low probability of having pro-condom attitudes (.13). Inconsistent Condom Users with High Dating Site Usage were characterized by having a high probability of spending two or more hours per day on dating sites (.77) and a low probability of consistent condom use (.43). This class exhibited relatively high probabilities of having pro-condom attitudes (.64) and pro-condom subjective norms (.67), but a low probability of self-efficacy for condom use (.34). Consistent Condom Non-Users were characterized by having a zero probability of consistent condom use. Furthermore, this class showed the highest probability of spending two or more hours per day on dating sites (.89). This class also exhibited a high probability of having pro-condom attitudes (.75), but a low probability of having pro-condom subjective norms (.29) and a low probability self-efficacy for condom use (.14). Table 2 shows the final latent class model for the present study.

\section{Discussion}

The present study identified four latent classes of online daters: Consistent Condom Users, Inconsistent Condom Users with Low Dating Site Usage, Inconsistent Condom Users with High Dating Site Usage, and Consistent Condom Non-Users. Consistent Condom Users had the highest probabilities of pro-condom attitudes, subjective norms, and self-efficacy cognitions, along with 
Table 2. Online daters' behavior and psychosocial construct classifications.

\begin{tabular}{|c|c|c|c|c|}
\hline \multirow{2}{*}{ Indicator } & Class $1^{\mathrm{a}}$ & Class $2^{b}$ & Class $3^{c}$ & Class $4^{\mathrm{d}}$ \\
\hline & $(17 \%)$ & $(23 \%)$ & $(40 \%)$ & $(20 \%)$ \\
\hline \multicolumn{5}{|l|}{$2+$ hours on dating site } \\
\hline Yes & 0 & 0 & .77 & .89 \\
\hline \multicolumn{5}{|c|}{ Attitudes about condom use } \\
\hline High (Pro-condom) & .73 & .13 & .64 & .75 \\
\hline Low & .27 & .87 & .36 & .25 \\
\hline \multicolumn{5}{|l|}{ Subjective norms } \\
\hline High (Pro-condom) & .80 & .69 & .67 & .29 \\
\hline Low & .20 & .31 & .33 & .71 \\
\hline \multicolumn{5}{|l|}{ Self-efficacy } \\
\hline High (Pro-condom) & .94 & .78 & .34 & .14 \\
\hline Low & .06 & .22 & .66 & .86 \\
\hline \multicolumn{5}{|l|}{ Consistent condom use } \\
\hline Yes & 1 & .66 & .43 & 0 \\
\hline
\end{tabular}

Bolded proportions highlight identifying characteristics of the class. a. Consistent condom users; b. Inconsistent condom users with low dating site usage; c. Inconsistent condom users with high dating site usage; d. Condom non-users.

a zero probability of spending $2+$ hours daily on dating site apps and a $100 \%$ probability of consistent condom use. Inconsistent Condom Users with Low Dating Site Usage showed moderately-high pro-condom self-efficacy cognitions, along with a zero probability of spending $2+$ hours daily on dating site apps and a moderate probability of consistent condom use. Inconsistent Condom Users with High Dating Site Usage showed moderate pro-condom attitudes and subjective norms, along with a moderately-high probability of spending $2+$ hours daily on dating site apps and a low probability of consistent condom use. Consistent Condom Non-Users had moderately-high pro-condom attitudes, but low pro-condom subjective norms and self-efficacy, along with the highest probability of spending $2+$ hours daily on dating site apps and a zero probability of consistent condom use.

The most desirable class, Consistent Condom Users, showed high probabilities of all three TPB psychosocial constructs, corresponding with consistent condom use. This finding aligns with previous research demonstrating the utility of the TPB constructs to influence condom use behavior (Carmack \& Lewis, 2009; Gibson et al., 2020). The low probability of consistent condom usage from the Inconsistent Condom Users with High Dating Site Usage (class 3) was interesting, as it showed a higher probability of pro-condom attitudes than Inconsistent Condom Users with Low Dating Site Usage (class 2), which had a lower probability of pro-condom attitudes, yet a higher probability of consistent condom use. This observation is contrary to previous research that purports 
attitudes to be the most salient psychosocial construct in the TPB that influences sexual risk behavior (Armitage \& Conner, 2001; Beadnell et al., 2008). Inconsistent Condom Users with High Dating Site Usage and Consistent Condom Non-Users had the lowest probability of consistent condom use, with the Consistent Condom Non-Users class being indicated by a zero probability of consistent condom use. These two classes showed the lowest probability of pro-condom subjective norms and self-efficacy, when compared to the other two classes. Of note, the Consistent Condom Users class had a very high probability of pro-condom self-efficacy (e.g., the belief that you can confidently wear a condom when you are going to have sex), while the Consistent Condom Non-Users class showed an overall low probability $(\mathrm{P}(\mathrm{A})=.14)$ of pro-condom self-efficacy. Taken together, the present findings align with previous research that indicated subjective norms and self-efficacy may have greater impacts on condom use behavior than attitudes among minority populations, in particular (Carmack et al., 2016; Carmack et al., 2015), as the present study utilized a racial-ethnically diverse sample.

\subsection{Contributions to the Sexual Risk Reduction Literature}

These findings contribute to the current literature in support of the TPB constructs' utility to differentiate classes of online daters, specifically, with regard to condom use. The findings also contribute to the literature in support of the utility value of subjective norms and self-efficacy's role in influencing condom use, particularly in racially and ethnically diverse online dating populations. As the classes progressed from consistent condom use, to inconsistent condom use, to no consistent use, the probability of having self-efficacy for condom use was lower in an observable trend. This trend observation may show that if we can raise condom use efficacy on the college campus, then perhaps this would strengthen consistent condom use. One's belief in their ability to use a condom is important when consensual sex is initiated and accepted. One seems more likely to wonder "Can I do this?" compared with their overall evaluation of a behavior (i.e., attitudes) and others' evaluation of their behavior (i.e., subjective norms). With emphases on self-efficacy and condom use communication, young adults should be encouraged to get to know a potential partner and ensure that condom use is acceptable and can be carried out before there is pressure to engage sexually.

Overall, the large majority of this online dating sample was classified as inconsistent condom users (83\%), with $20 \%$ of that proportion indicating no chance of consistent condom use. Characteristic of the highest condom use groups (classes 1 and 2) was a zero probability of high dating site usage $(2+$ hours per day), while the two groups with a lowest probability of consistent condom use (classes 3 and 4 ) were shown to have the highest probabilities of spending $2+$ hours per day interacting on dating sites. The Consistent Condom Non-Users showed an almost $90 \%$ probability of spending $2+$ hours on the dat- 
ing sites. A data trend can be observed in the findings as follows: As the probability of consistent condom use decreased across the classes, the probability of using a dating app for $2+$ hours increased within the classes. This finding aligns with previous research that implicates the relationship between amount of time on dating sites apps and condom non-use (Choi et al., 2016a). However, the present study identifies how varying probabilities of the TPB constructs relate to both time spent on dating apps and condom use.

\subsection{Practical Implications}

College campus-wide programs should be developed to target online daters. Specifically, programs or interventions could include aspects on how to communicate condom use prior to face-to-face meetups. This is an important consideration because meeting a potential relationship partner via the internet has been steadily displacing the roles of friends and family as the matchmaker for meaningful or casual relationship seeking (Rosenfeld et al., 2019; Spielhofer, 2010).

For many college students, they may be experimenting with sex and may not have ever contemplated the proper procedure or strategies in condom use communication when entertaining a new partner. Younger, less experienced emerging adults may be afraid to ask for a potential partner's STI testing records because they don't want to seem untrusting. Others may be shy and think about having the conversation, but fail to follow through. Perhaps demonstration classes could be implemented within college colloquiums, for example, on the best time to communicate condom use, put on a condom, and provide understanding of the benefits of using a condom. There could be in-person or recorded workshops or informational sessions that are held in student centers periodically. Young adults could be advised to practice carrying condoms (male or female) at all times, especially before face-to-face meetups.

The actual online dating platform offers opportunity for intervention if carried out with consideration for the intended demographic. Traditional sexual health messages may not gain traction in social media spaces for many reasons that are logical, given adolescent and emerging adult maturity (Byron et al., 2013). It is recognized that sexual education through social media apps may disrupt engagement comfort; however, it is speculated that sexual education through comedic entertainment would be more likely to capture their attention (Byron, 2013). Additionally, sexual health messages may be better received within an online dating app platform to which sexual interactions are expected to occur, more so, than within generic social media platforms (e.g., Facebook, Twitter).

There are still safety concerns with meeting a stranger online. There may be a fear of danger within the actual sexual encounter (Couch \& Liamputtong, 2008) following an online meeting. As such, college campus interventions for online daters and online dating etiquette should reinforce the filtering process (i.e. strategies used to ensure the authenticity of a potential partner met online). This 
may include the real-time exchange of online pictures, cross-referencing other social media accounts of the potential partner, and mobile text conversations. Online dating etiquette for online daters should also emphasize the need to insist that the initial meet-up occurs in a public place, which may lessen the likelihood of a sexual encounter during the first meet-and-greet. Taking the time to get to know a potential sex partner may add to the online filtering process, but should also be addressed for online daters within college populations.

These suggested college campus implementations should leverage college campus health centers and community health clinics. Condom use is associated with greater STI knowledge, the discussion of STI history prior to a sexual encounter, and perceived distress about an anticipated STI diagnosis (Cheng et al., 2018). College students may not realize that both condom use and STI testing are meant for everyone who has sex, not just people who participate in hook-ups or a "risky sex cultures." College and university health centers have the ability to provide take-home information (e.g. pamphlets) that are specific to online dating etiquette regarding condom use, STI risks, and danger risks. Information coming from these sources may be the most credible, as compared to individual online searches for health information. Individual internet searching is plagued with much misinformation, making it hard to decipher what is actually useful and true versus what is not. Approaching the topic from a medical prevention and treatment perspective that is fully supported by the college or university ensures that students receive accurate information on how to stay safe within their online dating communities. High schools may also serve as beneficial venues for implementing risk reduction in order to tackle condom use behavior prior to young adulthood, although the elucidation of sex remains controversial throughout many U.S. school systems. Notwithstanding, more research on the potential and actual effect of these implementations and research partnerships with university health centers is needed.

\subsection{Limitations}

There were some limitations to the present study. This sample was not representative of all college students; they were recruited through on online research platform specific to a single university in the U.S. The study was cross-sectional research, therefore we are unable to establish behavior over time. All data were self-reported, so there could be an issue of social desirability in responses. We attempted to mitigate this by giving participants a range of responses when inquiring about their consistent condom use. In other words, it may relieve cognitive dissonance for someone who rarely uses condoms to answer "almost always" or "most of the time", instead of "every time"; even though the former responses would still indicate inconsistent condom use. The results cannot be used to imply causation, as the methodological approach of LCA involves a person-centered methodology (e.g. groupings and classifications) and uses conditional probabilities, as opposed to actual events. 


\subsection{Future Research and Conclusions}

About $40 \%$ of internet users reported spending more time on social media than they did before the COVID-19 pandemic (Tankovska, 2021). Due to the fact that most Americans, especially those in densely populated cities, were under stay-at-home mandates during peak times of viral transmission, organic social interactions became limited. Perhaps social media, and likewise online dating entertainment, provided an outlet to nurture our psychological need for social interaction. Likewise, online dating has been steadily usurping traditional courtship for over a decade now. Future research should utilize quasi-experimental designs implemented within online dating site platforms to understand and address the effect of sexual health messaging on this specific population. Additionally identifying exactly which psychosocial cognitions within the TPB constructs have the greatest impact on a particular construct would help cater the most impactful messages for online daters. More research is needed in order to identify how the nuances of online dating are uniquely related to sexual behavior practices. Notwithstanding, other models of behavior and behavior change, such as the health belief model, could be applied to sexual risk behavior among online daters.

Dating site platforms offer the opportunity for implementing messages about pro-condom self-efficacy, subjective norms, and pro-condom attitudes to increase safer sexual practices. Spending 2 or more hours daily on dating site apps coincided with less consistent condom use with varying considerations regarding the TPB constructs. Targeting young adults through online dating site applications may allow for safe and open discussions about condom use and safe sexual practices as a way to reduce risky sexual behavior and increase condom use among emerging adult online daters.

\section{Acknowledgements}

Manuscript authorship (K.S.) was supported by the National Cancer Institute of the National Institutes of Health to the University of Houston under Award Number P20CA221697 and to MD Anderson Cancer Center under Award Number P20CA221696. The content is solely the responsibility of the authors and does not necessarily represent the official views of the National Institutes of Health.

\section{Conflicts of Interest}

The authors declare no conflicts of interest regarding the publication of this paper.

\section{References}

Ajzen, I. (1991). The Theory of Planned Behavior. Organizational Behavior and Human Decision Processes, 50, 179-211. https://doi.org/10.1016/0749-5978(91)90020-T

Armitage, C. J., \& Conner, M. (2001). Efficacy of the Theory of Planned Behaviour: A 
Meta-Analytic Review. British Journal of Social Psychology, 40, 471-499. https://doi.org/10.1348/014466601164939

Beadnell, B., Baker, S. A., Gillmore, M. R., Morrison, D. M., Huang, B., \& Stielstra, S. (2008). The Theory of Reasoned Action and the Role of External Factors on Heterosexual Men's Monogamy and Condom Use 1. Journal of Applied Social Psychology, 38, 97-134. https://doi.org/10.1111/j.1559-1816.2008.00298.x

Boonstra, A. M., Preuper, H. R. S., Balk, G. A., \& Stewart, R. E. (2014). Cut-Off Points for Mild, Moderate, and Severe Pain on the Visual Analogue Scale for Pain in Patients with Chronic Musculoskeletal Pain. Pain, 155, 2545-2550.

https://doi.org/10.1016/j.pain.2014.09.014

Byron, P., Albury, K., \& Evers, C. (2013). "It Would Be Weird to Have That on Facebook": Young People's Use of Social Media and the Risk of Sharing Sexual Health Information. Reproductive Health Matters, 21, 35-44. https://doi.org/10.1016/S0968-8080(13)41686-5

Carmack, C. C., \& Lewis-Moss, R. K. (2009). Examining the Theory of Planned Behavior Applied to Condom Use: The Effect-Indicator vs. Causal-Indicator Models. The Journal of Primary Prevention, 30, Article No. 659. https://doi.org/10.1007/s10935-009-0199-3

Carmack, C. C., Lewis, R. K., \& Roncancio, A. (2015). Get the Message: Targeting Beliefs to Develop Risk Reduction Intervention Messages for African American Adolescents. American Journal of Community Psychology, 55, 396-410. https://doi.org/10.1007/s10464-015-9719-x

Carmack, C., \& Rodriguez, L. (2018). Social Media Usage as a Correlate of STI Risk-Related Sexual Behavior on the College Campus: Moderating Effects of Gender. Current Psychology, 39, 1696-1704. https://doi.org/10.1007/s12144-018-9869-8

Carmack, C., Lewis, R. K., Roncancio, A., \& Gerecht, L. T. (2016). Guidelines for Construct Measurement Yielding Unexpected Higher-Order Constructs: An Application for the Theory of Planned Behavior Applied to Condom Use. American Journal of Psychology and Behavioral Sciences, 3, 25-33.

Carmack, C., Roncancio, A. M., Gerecht, L., \& Ansari. M. (2020). Perceived Partner beliefs about Condoms and Self-Efficacy Communication within the Context of the Theory of Gender and Power. Journal of Community Psychology, 48, 1424-1437.

https://doi.org/10.1002/jcop.22337

Cheng, Y., McGeechan, K., Bateson, D., Ritter, T. Weisberg, E., \& Stewart, M. (2018). Age Differences in Attitudes toward Safer Sex Practices in Heterosexual Men Using an Australian Internet Dating Service. Sex Health, 15, 223-231. https://doi.org/10.1071/SH17074

Choi, E. P. H., Wong, J. Y. H., Lo, H. H. M., Wong, W., Chio, J. H. M., \& Fong, D. Y. T. (2016a). The Association between Smartphone Dating Applications and College Students' Casual Sex Encounters and Condom Use. Sexual \& Reproductive Healthcare, 9, 38-41. https://doi.org/10.1016/j.srhc.2016.07.001

Choi, E. P. H., Wong, J. Y. H., Lo, H. H. M., Wong, W., Chio, J. H. M., \& Fong, D. Y. T. (2016b). The Impacts of Using Smartphone Dating Applications on Sexual Risk Behaviours in College Students in Hong Kong. PLoS ONE, 11, e0165394.

https://doi.org/10.1371/journal.pone.0165394

Couch, D., \& Liamputtong, P. (2008). Online Dating and Mating: The Use of the Internet to Meet Sexual Partners. Qualitative Health Research, 18, 268-279. https://doi.org/10.1177\%2F1049732307312832

Eggermont, S. (2004). Television Viewing, Perceived Similarity, and Adolescents' Expec- 
tations of a Romantic Partner. Journal of Broadcasting and Electronic Media, 48, 244-265. https://doi.org/10.1207/s15506878jobem4802 5

Gibson, L. P., Gust, C. J., Gillman, A. S., Bryan, A. D., \& Ewing, S. W. F. (2020). Mechanisms of Action for Empirically Supported Interventions to Reduce Adolescent Sexual Risk Behavior: A Randomized Controlled Trial. Journal of Adolescent Health, 67, 53-60. https://doi.org/10.1016/j.jadohealth.2020.01.004

Gomes, A. I. C. D. S., \& Nunes, M. C. S. (2017). Predicting Condom Use: A Comparison of the Theory of Reasoned Action, the Theory of Planned Behavior and an Extended Model of TPB. Psicologia: Teoria e Pesquisa, 33, e33422.

Hansen, C., \& Krygowski, W. (1994). Arousal-Augmented Priming Effects: Rock Music Videos and Sex Object Schemas. Communication Research, 21, 24-47. https://doi.org/10.1177\%2F009365094021001003

Lo, Y., Mendell, N. R., \& Rubin, D. B. (2001). Testing the Number of Components in a Normal Mixture. Biometrika, 88, 767-778.

https://doi.org/10.1093/biomet/88.3.767

Martino, S., Collins, R., Elliott, M., Strachman, A., Kanouse, D., \& Berry, S. (2006). Exposure to Degrading versus Nondegrading Music Lyrics and Sexual Behavior among Youth. Pediatrics, 118, e430-e441. https://doi.org/10.1542/peds.2006-0131

Montanaro, E. A., Kershaw, T. S., \& Bryan, A. D. (2018). Dismantling the Theory of Planned Behavior: Evaluating the Relative Effectiveness of Attempts to Uniquely Change Attitudes, Norms, and Perceived Behavioral Control. Journal of behavioral medicine, 41, 757-770. https://doi.org/10.1007/s10865-018-9923-x

Morales, A, Tomczyk, S., Orgilés, M., \& Espada, J. P. (2021). "Who Are at Higher Sexual risk?" Latent Class Analysis of Behavioral Intentions among Spanish Adolescents. International Journal of Environmental Research and Public Health, 18, Article No. 1855. https://doi.org/10.3390/ijerph18041855

Nylund, K. L., Asparouhov, T., \& Muthén, B. O. (2007). Deciding on the Number of Classes in Latent Class Analysis and Growth Mixture Modeling: A Monte Carlo Simulation Study. Structural Equation Modeling: A Multidisciplinary Journal, 14, 535-569. https://doi.org/10.1080/10705510701575396

Pew Research Center (2020). The Virtues and Downsides of Online Dating. https://www.pewresearch.org/internet/2020/02/06/the-virtues-and-downsides-of-onlin e-dating/

Robison-Chadwell, A. (2017). US Young Adults STDs, Risk Perception, Risk Behaviors, and Health Information Seeking. Ph.D. Thesis, Minneapolis, MN Walden University.

Rosenfeld, M. J., Thomas, R. J., \& Hausen, S. (2019). Disintermediating Your Friends: How Online Dating in the United States Displaces Other Ways of Meeting Affiliations. Proceedings of the National Academy of Science of the United States of America, 116, 17753-17758. https://doi.org/10.1073/pnas.1908630116

Salim, S. (2019). Time Spent on Social Media. https://www.digitalinformationworld.com/2019/01/how-much-time-do-people-spendsocial-media-infographic.html

Spielhofer, T. (2010). Children's Online Risks and Safety: A Review of the Available Edvience. Slough: National Foundation for Educational Research.

https://www.nfer.ac.uk/publications/COJ01/COJ01.pdf

Tankovska, H. (2021). Estimated U.S. Social Media Usage Increase Due to Coronavirus Home Isolation 2020.

https://www.statista.com/statistics/1106343/social-usage-increase-due-to-coronavirus- 
home-usa/

The New Media Institute. (n.d.). About New Media Institute. https://mynmi.net/about/

Trafimow, D., \& Fishbein, M. (1994). The Moderating Effect of Behavior Type on the Subjective Norm-Behavior Relationship. Journal of Applied Social Psychology, 134, 755-763. https://doi.org/10.1080/00224545.1994.9923010

Turchik, J. A., \& Gidycz, C. A. (2012). Prediction of Sexual Risk Behaviors in College Students Using the Theory of Planned Behavior: A Prospective Analysis. Journal of Social and Clinical Psychology, 31, 1-27. https://doi.org/10.1521/jscp.2012.31.1.1

Ward, L. (2003). Understanding the Role of Entertainment Media in the Sexual Socialization of American Youth: A Review of Empirical Research. Developmental Review, 23, 347-388. https://doi.org/10.1016/S0273-2297(03)00013-3

Ward, L., \& Friedman, K. (2006). Using TV as a Guide: Associations between Television Viewing and Adolescents' Sexual Attitudes and Behavior. Journal of Research on Adolescence, 16, 133-156. https://doi.org/10.1111/j.1532-7795.2006.00125.x

Whitty, M. T., \& Carr, A. N. (2006). Cyberspace Romance: The Psychology of Online Relationships. London: Palgrave McMill. 